\title{
GPS Fencing based Secured Transportation for Liquid Material
}

\author{
Mahek Bhagat \\ UG Student, EC \\ LIT, Sarigam, INDIA
}

\author{
Jinesh Bhandari \\ UG Student, EC \\ LIT, Sarigam, INDIA
}

\author{
Siddhi Desai \\ Asst.Professor \\ LIT, Sarigam, INDIA
}

\begin{abstract}
Nowadays, Transportation of Liquid materials such as oil and petrochemical products is very prone to theft and tampering. So in this paper, system for secured transportation of liquid materials is introduced. In this project, GPS and GSM are used as a core technology with hardware control by Arduino. A liquid transportation tank is equipped with GPS tracking module. GPS will continuously monitor the location of system. As soon as tanker comes in geo-fencing area it then only it allow to do authentication through password, if in between any person has access lock, it send security alert to owner. Once the target location is matched it allows operating the lid lock and dispensary valve box lock. In addition Accelerometer is used for monitoring speed of the vehicle and gives alert to the driver if speed is increased beyond predefined speed limit. Through GSM module, the location of tanker, speed and lock status is sent to the owner at regular interval which helps in monitoring the tanker. In emergency cases like damage of lock or accident, when driver press push button, emergency message along with latitude and longitude information is sent to the owner and client .So owner and client can take necessity actions.
\end{abstract}

\section{General Terms}

Locking system, pass-code authentication, Location based authentication

\section{Keywords}

Arduino Mega, GPS, GSM, Accelerometer, Numeric Keypad.

\section{INTRODUCTION}

In the present situation, transporting the oil and petroleum products without any security system in the vehicle leads the theft or adulteration of product by the unauthorized access of tanker. According to study, In India there are such many cases of petroleum product thefts have been reporting. Everyday about 10500 litres of petroleum products are theft on the route of Nepal Oil Corporation to Baitalpur of India. There are such many examples of petroleum theft is noted. So, to solve such problems, an advanced security system in the vehicle is used for transportation of chemical and petroleum products. In this project, Arduino Mega2560 board is used for processing data. Using GPS and GSM/GPRS technologies one can avoid the intermediate access to the petroleum products during transportation. To provide security, system is made password protected. Thus, the human intervention is eliminated in transportation the system is accessed only at the source or the destination. At the source or the destination, user has to enter valid password and afterward only user can access the lock. If in between lock is opened, then System will alert the owner where lock gets opened. Here accelerometer is used for speed monitoring of vehicle. If driver crosses the predefined limited speed then system will give warning to the driver to reduce the speed of vehicle. In emergency case, driver has to press emergency button (push button), so emergency message along with latitude and longitude information is sent to the owner and client .So owner and client can take necessity actions.

This paper is organized as follows. This section gives an introduction about GPS-fencing based secured transportation for liquid materials. In section II, a review about various techniques for secured transportation using GSM \& GPS technologies is presented. In section III Design \& Implementation with Test results is explained briefly. The conclusion is given in section IV.

\section{LITERATURE SURVEY}

In the year 2015, Mr. Pawale S. R., Mr. M. M. Bokare, Dr. V. M. Thakare, Dr. Mrs. Sadhana Chidrawar has Introduced a system "Low cost SMS based Vehicle Tracking system using Android" in which client just sends one message to the vehicle and the vehicle mobile will send you current location of your vehicle in the form of web link and user has to click on a link and that link goes to google map and will show the current location of our vehicle [1].

In the year 2016, Authors Puneeth Rao, Aravind Rao has introduced a system "Location Based Locking System for Transportation" comprising of GPS \& GSM technology to keep track on vehicle's location and to communicate with system. This system uses, Arduino Mega 2560 as central processing unit to process the data obtained from various modules connected to it. The controller compares the data obtained from GPS with predefined location and if the vehicle is in Geo-fenced location, system allows user to enter password. Once user enters the password through keypad and if it matches with predefined password, the system allows user to access container. In case of any Tampering with container during transportation, FRS pressure sensor senses applied pressure and microcontroller sends alert message to owner and then container can be opened only by RFID authentication.

But Limitation of this System are, It does not provide on demand current location. Moreover, It does not allow user to shift the material from one container to other when it is not in geo-fencing [3].

In the year 2016, Authors Mangesh Kolaskar,Aniket Chalke, Madhura Borkar, Kedar Naik, Dr. B.K Lande \& Prof. Varsha Suralkar proposed a system "Real Time and Offline GPS Tracker using Arduino" in which user makes a call to registered number in GPS-GSM module. After that the vehicle's location coordinates is sent to owner through the SMS. These data will be stored in memory card in every 10 seconds and then it will be uploaded in Google fusion table to view in Google maps [4].

\section{DESIGN AND IMPLEMENTATION}

This project contains several feature like geo-fencing, keypad based password authentication, alert message when lock gets open before destination, speed monitoring through 
accelerometer, unlocking of lock in emergency cases. Arduino mega 2560 micro-controller board is used to communicate with different components like GSM, GPRS, accelerometer, sensor, keypad, LCD display, Arduino Mega 2560 processes the input data and give required output. GPS module and accelerometer sensor are used as input device for microcontroller. GPS is used to obtain location co-ordinates in terms Latitude and Longitude. It is used to create a geofencing of location. As the system enters in geo-fencing Area, keypad will automatically power up by controller. After that it allows the user to enter password. After successful authentication of password, user can access the lock of the tanker. GSM is used to send and receive the message. If within Geo fencing area, lock is opened then it alerts owner by notifying through SMS. In emergency cases like damage of lock or accident, when driver press push button, emergency message along with latitude and longitude information is sent to the owner .So owner can take necessity actions. This system allows to open the lock by two way authentication by owner and client. At regular interval, it sends the data given by the accelerometer and status of tanker's lock to the owner. So, it is used for speed monitoring and helps driver to maintain the speed limit of truck within predefined range. For the safety of vehicle, Push button is provided in the system. In emergency circumstances, if driver presses the push button, Emergency message will be sent to the owner. So, owner can take appropriate action.

\subsection{Block Diagram}

\section{Mobile Unit in Truck Tanker}

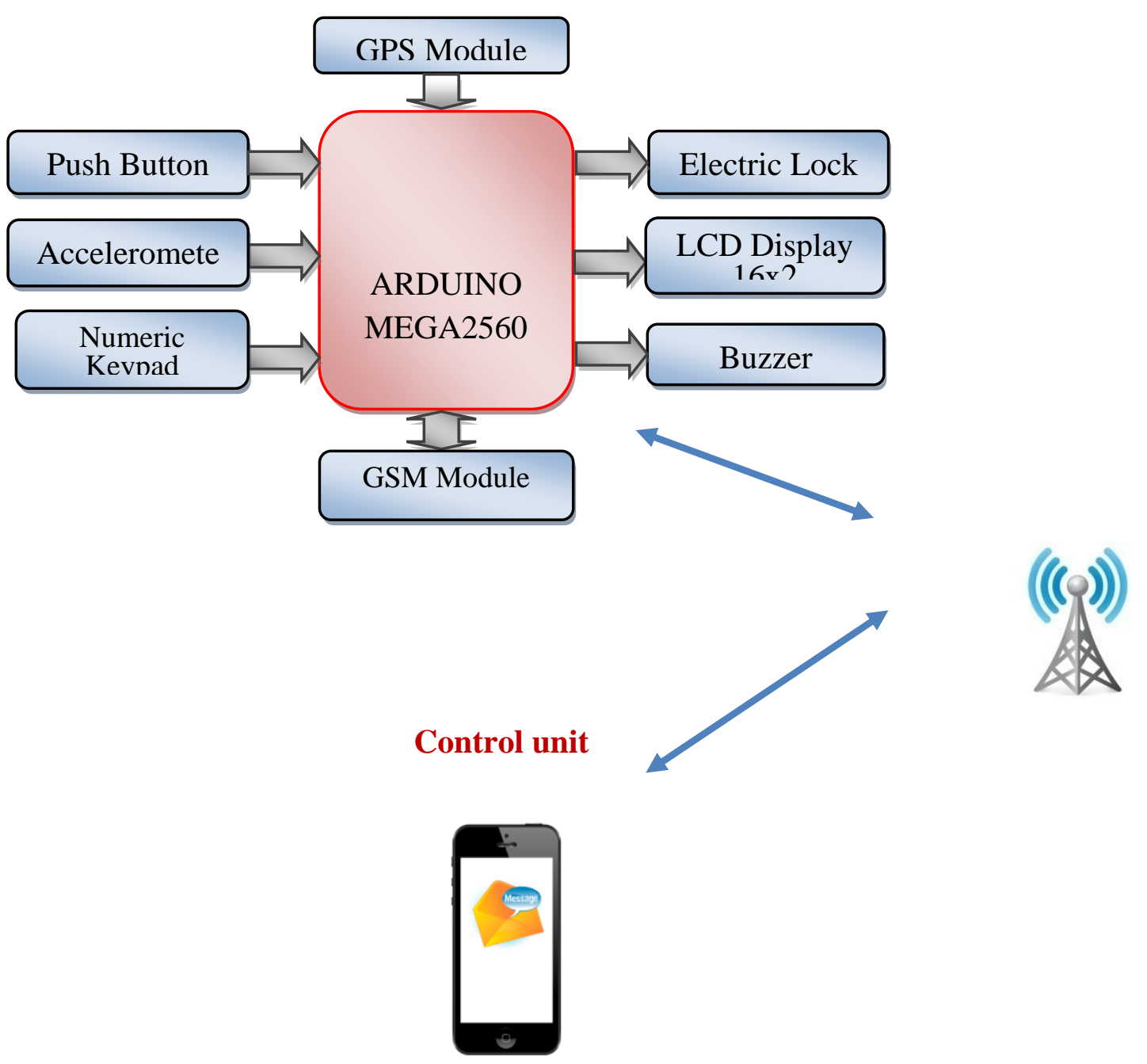

Fig 1: Block Diagram GPS Fencing Based secured transportation for liquid material 


\subsection{Flow Chart}

\subsubsection{Normal Routine}

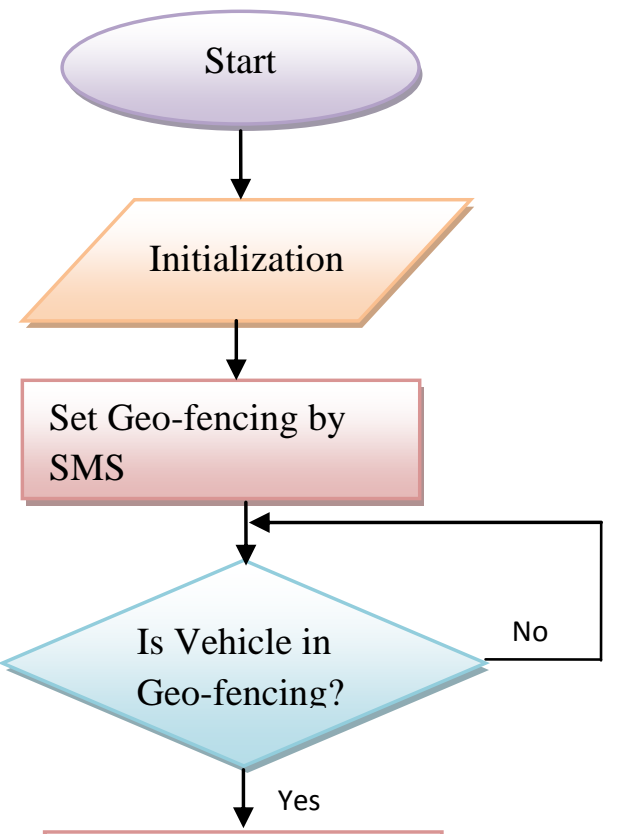

Allow the user to enter the pass-code

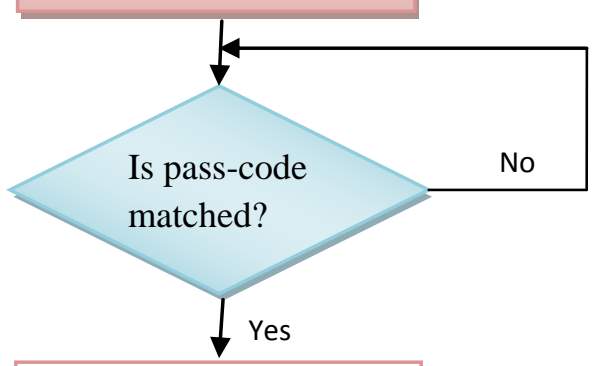

Allow the client to access the lock?

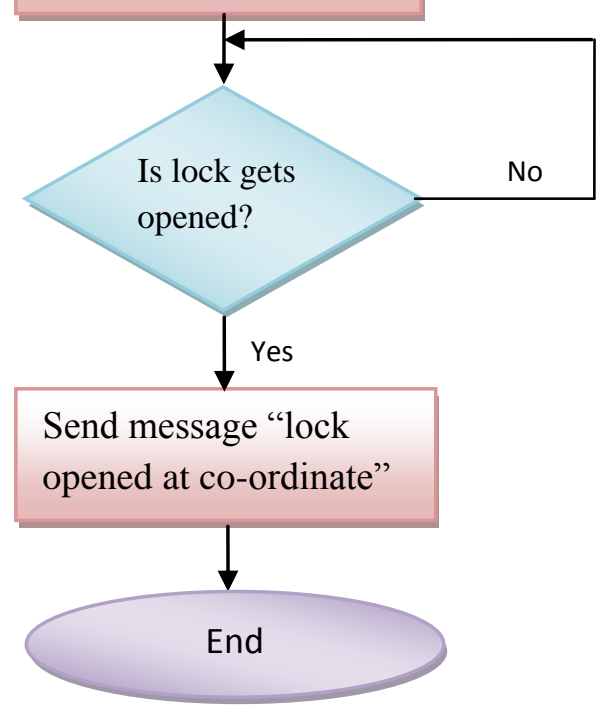

Fig 2: Flow chart GPS Fencing Based secured transportation for liquid material

\subsubsection{Emergency}
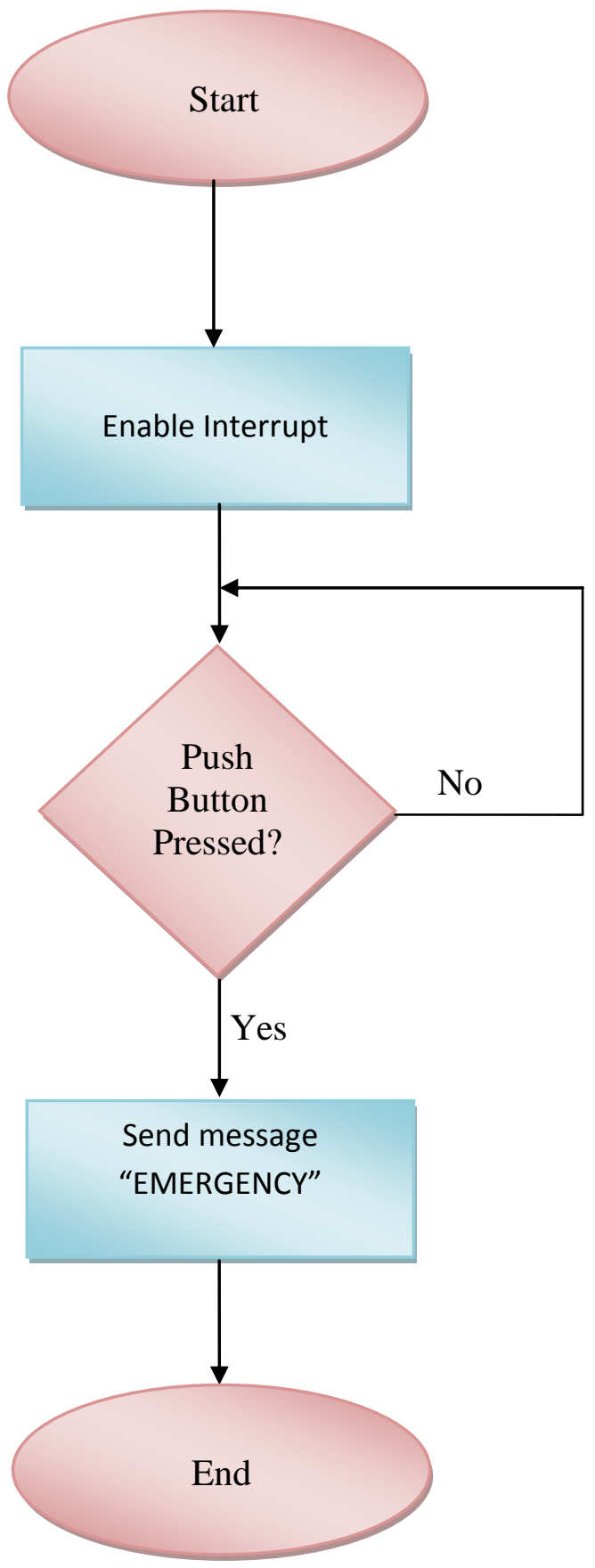

Fig 3: Flowchart (for Interrupt) 


\subsubsection{Speed Monitoring}

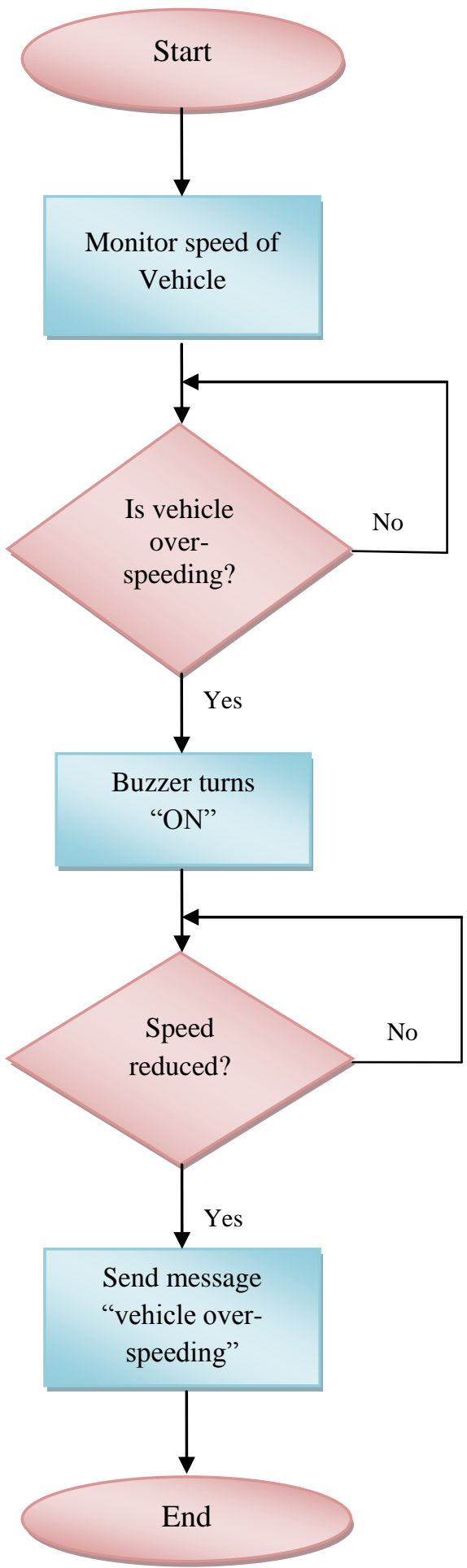

Fig 4: Flowchart (for Speed monitoring)

\subsection{Working}

(Normal Routine)

The process starts with the owner sending message which contains the "Location co-ordinates of both the source \& destination" to the registered number. Then controller board will process the location co-ordinates obtained through SMS and it will set the Geo-fencing area of both the source \& destination location. Now controller will monitor the location through GPS module, and if the vehicle is in Geo-fencing area then only it will allow the user to enter the password. After the password is entered it will check whether the password is matched or not. If the entered password is matched then it will allow the user to access the Lock of container. Now as the lock gets opened by user, it will send the message "Lock opened at co-ordinate" to the owner and client both.

(Emergency)

The process starts with the driver of vehicle pressing the "Push Button "in some emergency situations such as accidents. By pressing the push button the normal routine is stopped and the system sends the message "EMERGENCY" along with vehicle's current location through GSM modem to the owner and client. So, the owner and client can take the appropriate actions.

\section{(Speed Monitoring and Controlling)}

Accelerometer will continue gets the speed of vehicles. As soon as speed of vehicle increase from the predefined speed ,buzzer will start alerting the driver to reduce speed and also display over speeding message on LCD display .If driver don't reduce with $3 \mathrm{~min}$ controller send the message to the owner with speed and location so that necessary action can be taken.

\subsection{Implementation results}

Step 1: Owner or controller has to send Source and destination's Coordinates location through SMS to registered number for creating geo fencing once material is loaded in vehicle.

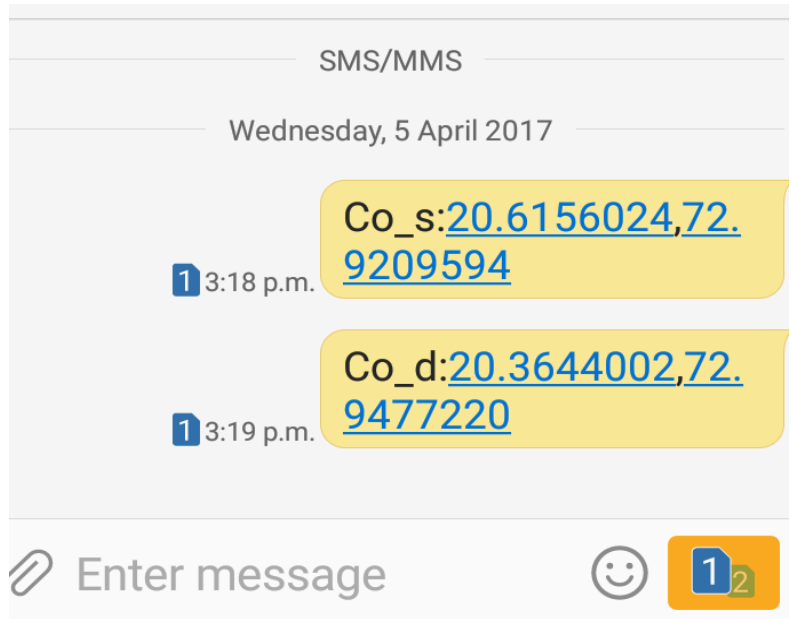

Fig 5: Creating the Geo-fencing by SMS

Step 2: Once vehicle entered in geo fencing area, it display output "Vehicle in Geo Fencing Area" and GPS module start monitoring Location. 


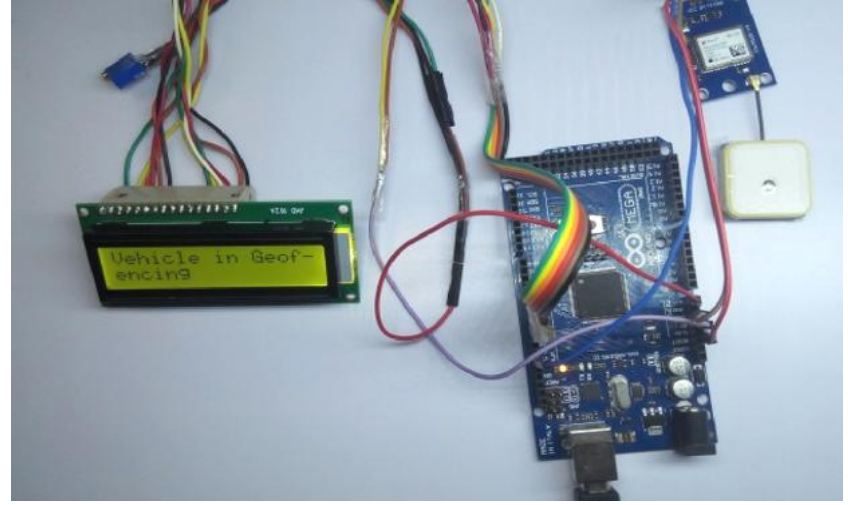

Fig 6: Vehicle in Geo-fencing

Step 3: When it reach at destination location, it give notification to owner and client that vehicle reached at destination and it allow user to enter password.

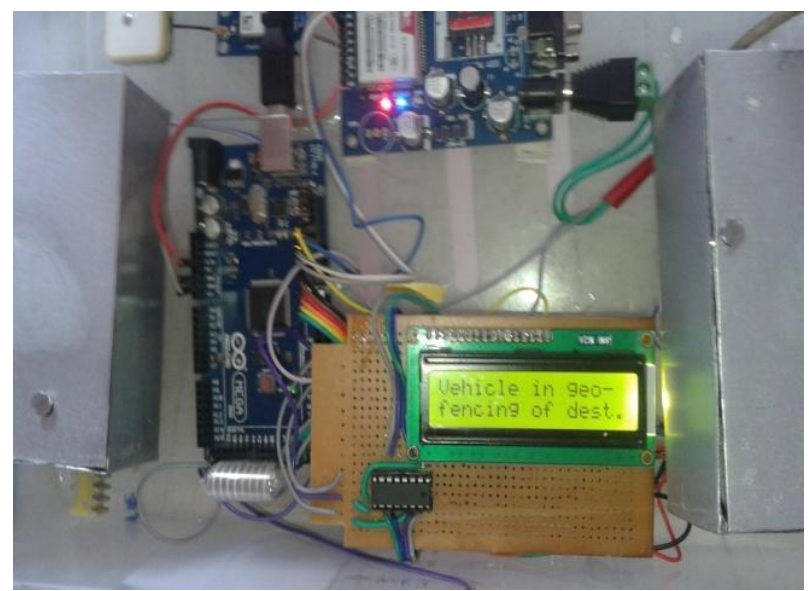

Fig 7: Notification of vehicle reached at destination

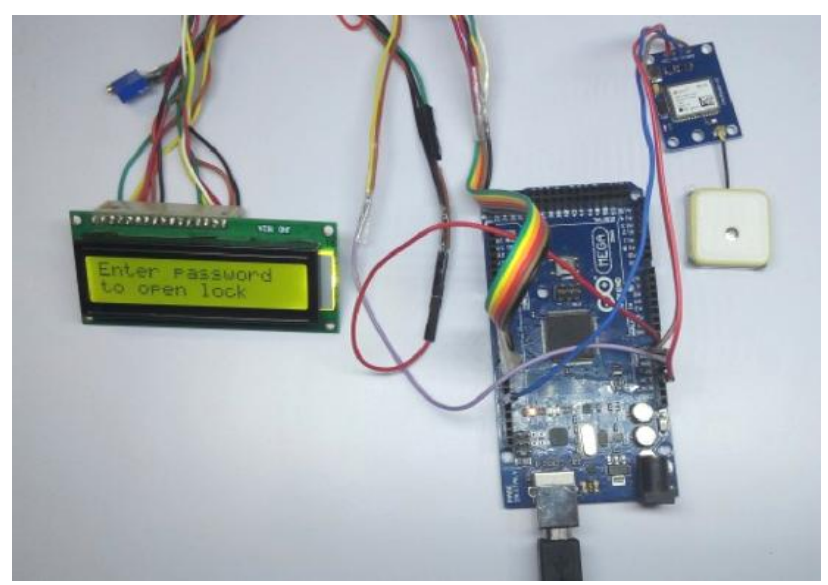

Fig 8: Password authentication

Step 4: Once user enter password, Microcontroller will check whether it is matched or not.

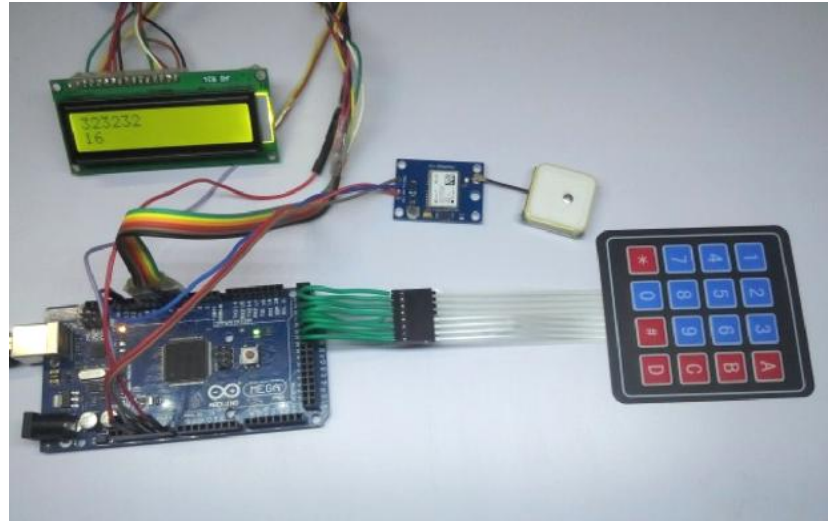

Fig 9: Password authentication

Step 5: If password is matched, it allow unlocking the lock.

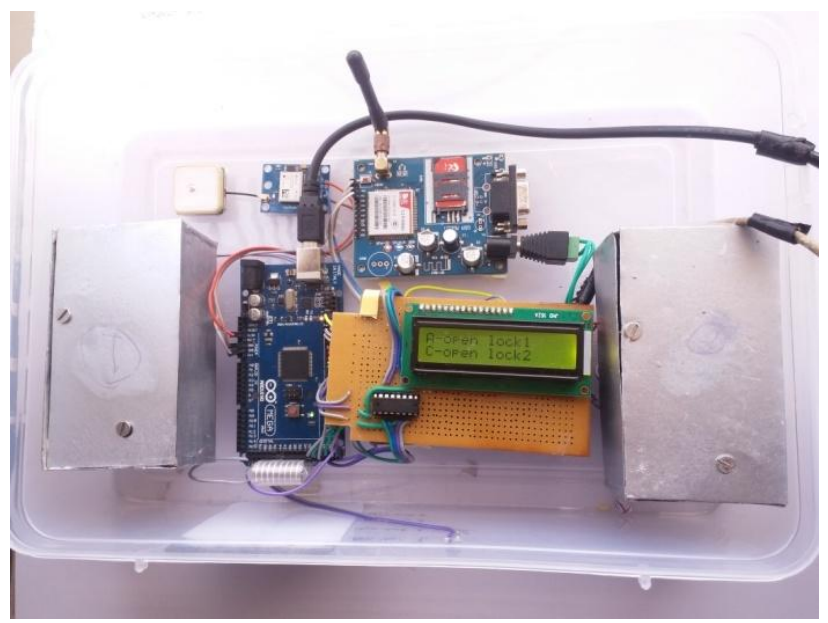

Fig 10: Options to Unlock

Step 6: If password is not matched, it not allow unlocking the lock by informing user about wrong password and informed user to re-enter the password.

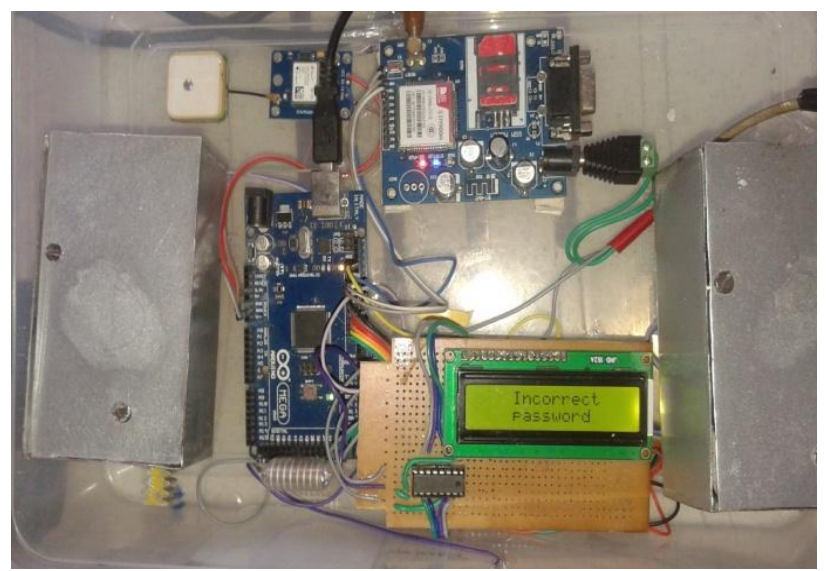

Fig 11: Notification for Incorrect password 


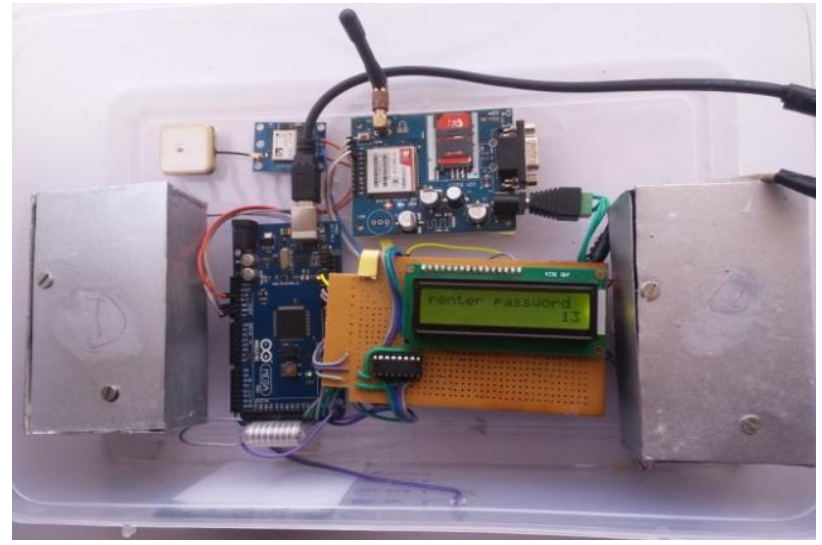

Fig 12: Notification for re-enter password

Step 7: If in middle someone try to access lock, it send Alert message along with latitude and longitude where the lock get opened through SMS to owner.

\section{Lock opened at 20.61 $\underline{59643,72.9209442}$}

Fig 13: Alert message received by owner

Step 8: In case of emergency, when driver presses push button, Emergency message along with latitude and longitude information is sent through SMS to owner.

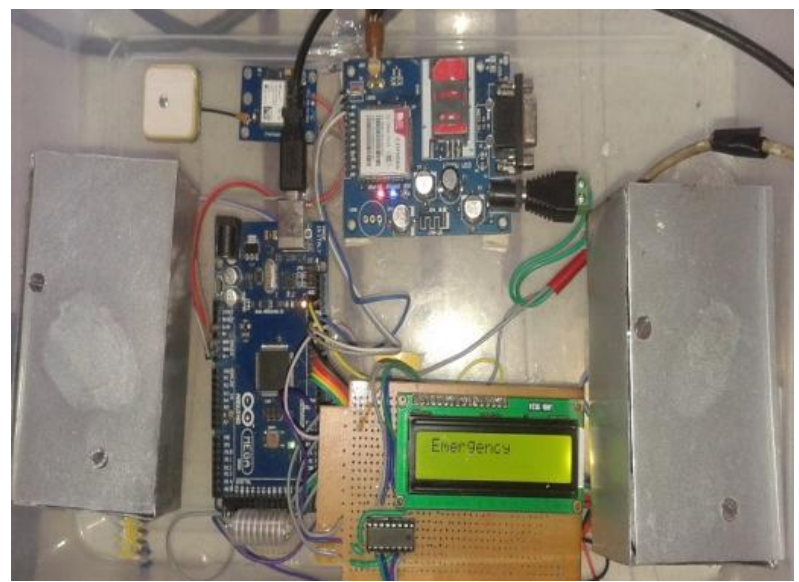

Fig 14: Indication of emergency by driver

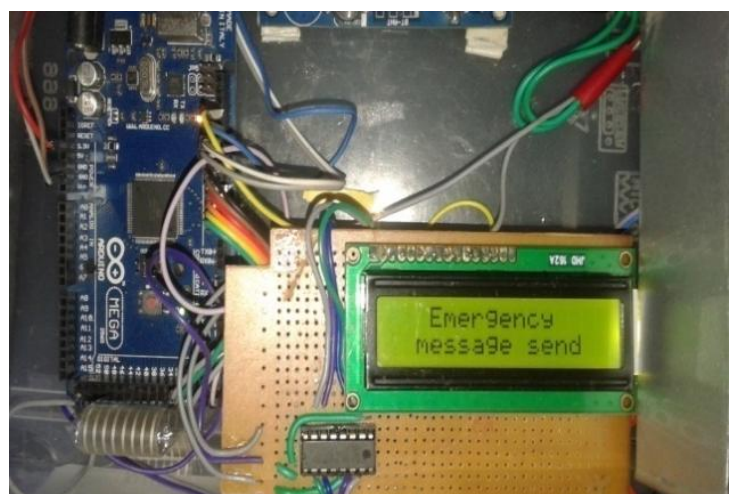

Fig 15: Notification that emergency message is sent to owner

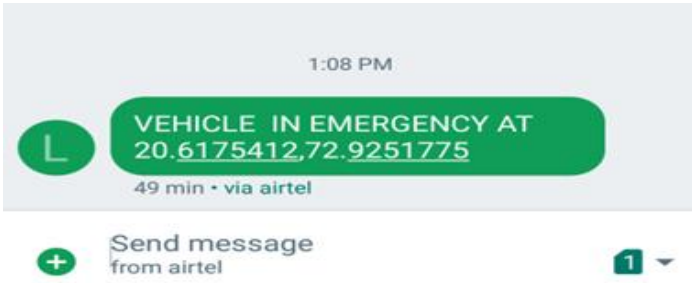

Fig 16: Emergency Message received by owner

Step 9: If vehicle goes beyond predefined speed limit, system will automatically alert driver through buzzer and notify driver to reduce speed and also display over speeding message on LCD display.

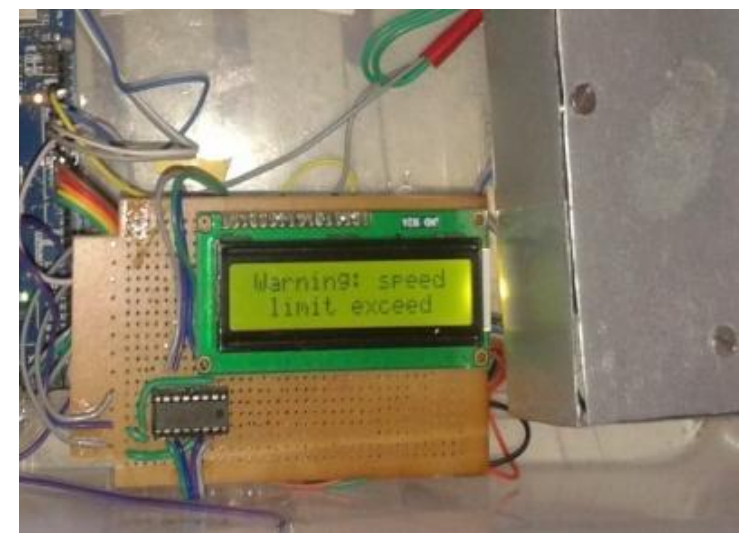

Fig 17: Warning driver for vehicle speed exceed

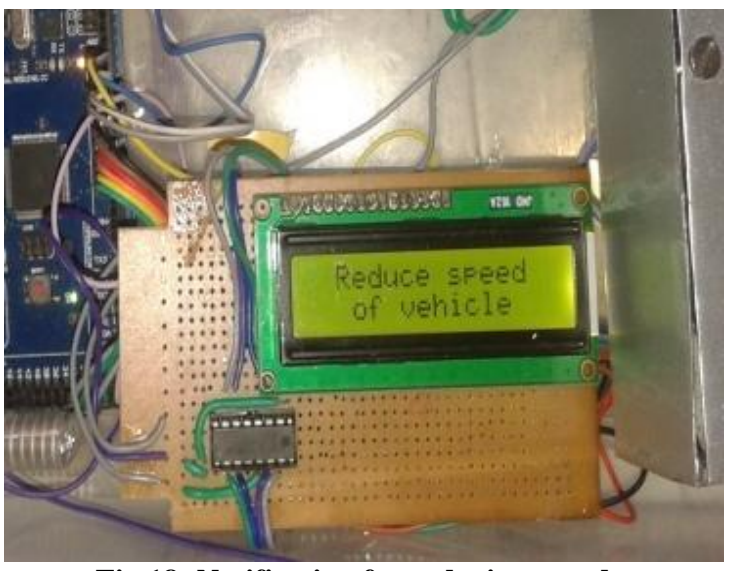

Fig 18: Notification for reducing speed

\section{CONCLUSION}

Transportation of liquid materials such as petroleum is very prone to theft which leads in its adulteration. This incurs heavy losses to Industries. So the security during transportation of liquid materials is of prime importance. By this system, the security issue of transporting the liquid materials can be solved by creating Geo fencing. It allow to access tanker's lock only when vehicle reaches in geo-fencing source and destination locations. If in between any person has access lock, it send security alert to owner. Through Accelerometer speed of the vehicle is monitored. If speed is increased beyond predefined speed limit, system automatically alerts the driver. This On-demand current location \& notification message through SMS provision of "vehicle's over-speeding" is the additional features for safe \& secured transportation. Through GSM module, the location of tanker, speed and lock status is sent to the owner at regular interval which helps in monitoring the tanker. In emergency 
cases like damage of lock or accident, when driver press push button, emergency message along with latitude and longitude information is sent to the owner and client .So owner and client can take necessity actions. The Implementation of emergency notification also gives privileges such as to allow shifting of the product from the current vehicle to other container in case if vehicle gets damaged.

\section{FUTURE SCOPE}

This project work can be extended by adding features such as for recording information like speed, lock status, GPS location in data logger module at regular interval.

\section{ACKNOWLEDGMENT}

The authors are grateful to all their colleagues for their useful comments and cooperation on many topics related to this work. Also, we would like to thank our organization and staff members for the support and the facilities that have been provided to us.

\section{REFERENCES}

[1] Mr. Pawale S. R. , Mr. M. M. Bokare , Dr. V. M. Thakare, Dr. Mrs. Sadhana Chidrawar, "Low Cost SMS
Based Vehicle Tracking System Using Android", International Journal of Application or Innovation in Engineering \& management (IJAIEM) Volume 4, Issue 4, April 2015

[2] Farhan Ramju , Ramadhani S. Sinde , Shubi Kaijage , "Development and Testing of Adaptive Vehicle Speed Monitoring System integrated with Alcoholic Detector for Public Buses", International Journal of Computer Applications (0975 - 8887) - Volume 127 - No.7, October 2015.

[3] Puneeth Rao, Aravind Rao,“ Location Based Locking System for Transportation" , International Journal of Engineering and Techniques - Volume 1 Issue 6, Jan Feb 2016

[4] Mangesh Kolaskar, Aniket Chalke, Madhura Borkar, Kedar Naik, Dr. B.K Lande \& Prof. Varsha Suralkar, "Real Time and Offline GPS Tracker Using Arduino", (IJIR) Vol-2, Issue-5, 2016 